\title{
SYMPHYSIS MORPHOLOGY AND DIMENSIONS IN DIFFERENT VERTICAL FACIAL PATTERNS (CBCT SCAN STUDY)
}

\author{
Mohamad Mahfoud, Hazem Hassan \\ Orthodontics and Dentofacial Orthopedic Department, Tishreen University, Lattakia, Syria
}

\begin{abstract}
Mandibular symphysis (MS) morphology is a valuable diagnostic and treatment-planning tool in orthodontics. It is utilised as a reference measure for esthetic purposes, specifically in the lower part of the face, as well as to predict the direction of the mandibular growth rotation as the vertical growth direction. The aim of the presenting study is to use cone beam computed tomography (CBCT) to evaluate the MS morphology and dimensions of adults with different vertical facial patterns and had no previous orthodontic treatment. The study consisted of 100 subjects (42 males and 58 females). Mean age of subjects is 27.6 years (average age of men 29.2 years, average age of women 26.4 years). The СBCT images were obtained by Scanora 3D. The evaluation of the different vertical facial patterns was carried out according to Björk and Jarabak. Six lines, four angles and one area were used in the mandibular symphysis study. The study revealed varying correlations between the parameters of the mandibular symphysis and those of the vertical facial patterns. It was found that the convexity of the mandibular symphysis (B-POG-Me) and the distance from POG to the z-axis (POG-Z Axis) are highly correlated to the parameters evaluating the vertical facial patterns. The angle between the Gonion-Nasion line and the mandibular plane (GO2Angle) and the angle between the palatal and mandibular planes (B-Angle) were highly correlated to the measurements used on the mandibular symphysis.
\end{abstract}

Keywords: cone beam computed tomography, СВСТ, mandibular symphysis morphology, mandibular symphysis dimensions, vertical facial patterns

\section{INTRODUCTION}

Mandibular symphysis (MS) morphology is a valuable diagnostic and treatment-planning tool in orthodontics. It is used as a reference measure for esthetic purposes, specifically in the lower part of the face. The MS morphology governs the position of the lower incisor during orthodontic and orthognathic surgery. (1-4)

It has been shown that restricting the movement of the lower incisor within the bone structure can enhance stability, periodontal health and prevents root resorption. $(5,6)$

Many factors contribute to the symphyseal growth and morphology. These include the functional neuroskeletal balance (7), masseter muscle thickness (8), mandibular plane angle $(4,9)$, overbite (10-12), vertical jaw relationships $(13,14)$, inclination of the lower incisors $(15,16)$, occlusal hy- pofunction and its recovery (17), inheritance (18), and more.

Mandibular symphysis can also be utilized to predict the direction of the mandibular growth rotation. This is because the vertical growth direction has an indirect effect on the MS through affecting the anteroposterior position of the mandible $(19,20)$.

A couple of studies assessed the MS morphology and dimensions in Class I, II and III malocclusions. However, the effects of the vertical facial patterns have not been specified.

Cephalometric analysis is frequently used by orthodontists as a treatment-planning tool (21). It can be used to analyze the dental and skeletal relationships prior to the treatment and as a method of evaluating the treatment progress. However, cephalometric radiographs present some diagnostic limitations such as errors in the identification of landmarks, errors during tracing and structure dis- 
tortion and magnification of the craniofacial complex as the radiograph is a two dimensional image of a three-dimensional structure (22).

In order to circumvent such limitations, the use of medical computed tomography (CT) was introduced in some dental specialties $(23,24)$. This scan helped reveal the hidden structures, however, the quality of the resulting image was damaged by artefacts produced by the metallic brackets. The reduced quality in addition to the high cost and high radiation exposure compromised its use for orthodontic purposes $(25,26)$.

Cone beam computed tomography (CBCT) has overcome the above problems by producing a single 3D image of the craniofacial complex combining all the conventional orthodontic images such as panoramic radiographs and full periapical (27). CBCT imparts a radiation dose that is 10 times lower than medical tomographs and has a superior spatial resolution for a lower cost (28).

\section{STUDY OBJECTIVES}

The aim of the presenting study is to use cone beam computed tomography (CBCT) to evaluate the MS morphology and dimensions of adults with different vertical facial patterns and had no previous orthodontic treatment.

\section{MATERIALS AND METHODS}

\section{Subjects}

The criteria for selecting the subjects are as follows:

- Age range (18-35 years).

- Subjects selected at random in terms of sex, type of malocclusion and growth model.

- No history of orthodontic treatment.

- No history of trauma to the dento-facial structures.

- Subjects must have fully erupted permanent dentition up to second permanent molar.

- No supernumerary teeth/missing teeth/impacted teeth.

- No congenital anomalies/evident signs of neurological impairment and/or syndromes and/or dentoskeletal asymmetries and/or craniofacial malformation.

The study consisted of 100 subjects (42 males and 58 females) who have undertaken a CBCT scan for purposes other than this study. Mean age of subjects was 27.6 years (average age of men 29.2 years, average age of women 26.4 years).

\section{CBCT study}

The CBCT scans were obtained by Scanora 3D CBCT (Soredex, Tuusula, Finland), under the following conditions: voxel size of $0.25 \mathrm{~mm}$ (FOV $130 \times 145 \mathrm{~mm}$ ), tube voltage of $85 \mathrm{kV}$, current of $15 \mathrm{~mA}$, and scanning time of 3.7 seconds.

The CBCT scan data was processed and reformatted by the OnDemand3D Application program, version 1.0.8.0408 (CyberMed Inc, Seoul, Korea).

Image orientation was established by three reference planes:

- The axial plane, passing through the right and left orbitale points as well as the right Porion.

- The coronal plane, passing through the left and right porion perpendicular to the chosen axial plane (29-32). (Fig. 1)

- The sagittal plane, median plane of the mandibular, passing through the labial cortical plate, mental process center, and mandibular ramus center, perpendicular to the chosen axial and coronal planes (16). (Fig. 2)
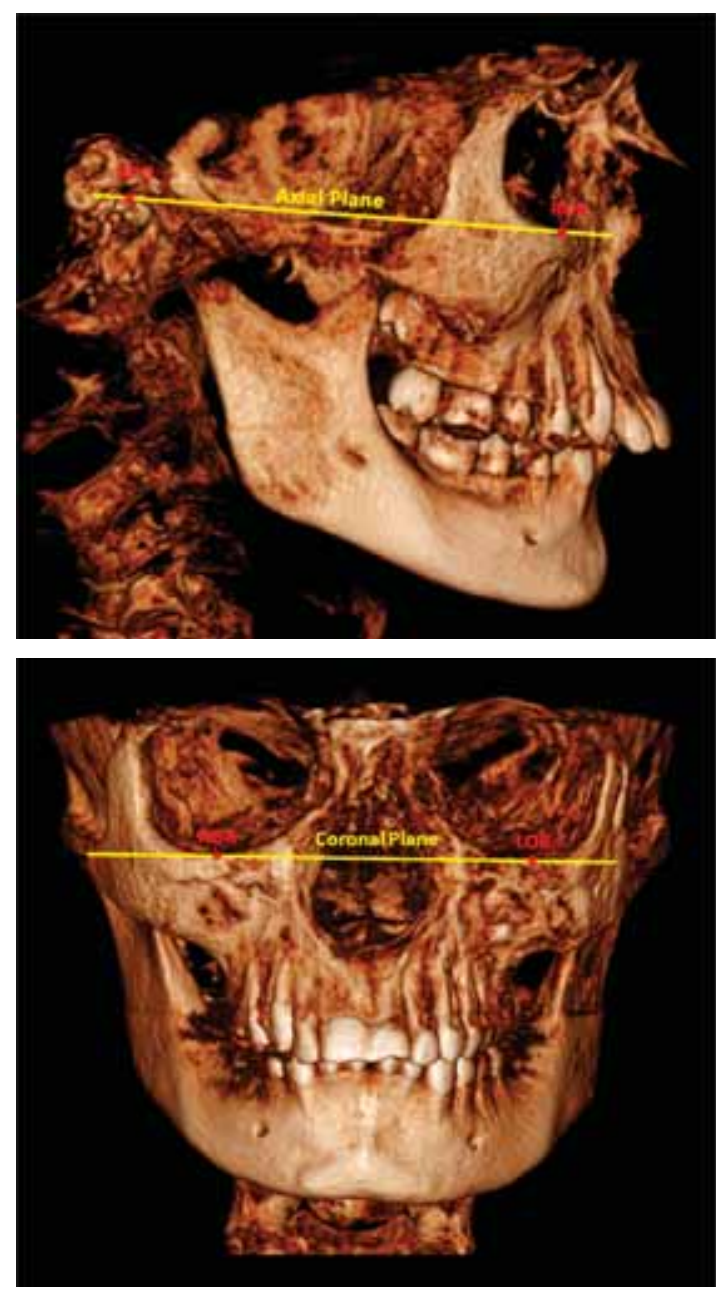

FIGURE 1. Definition of the axial plane and the coronal plane 

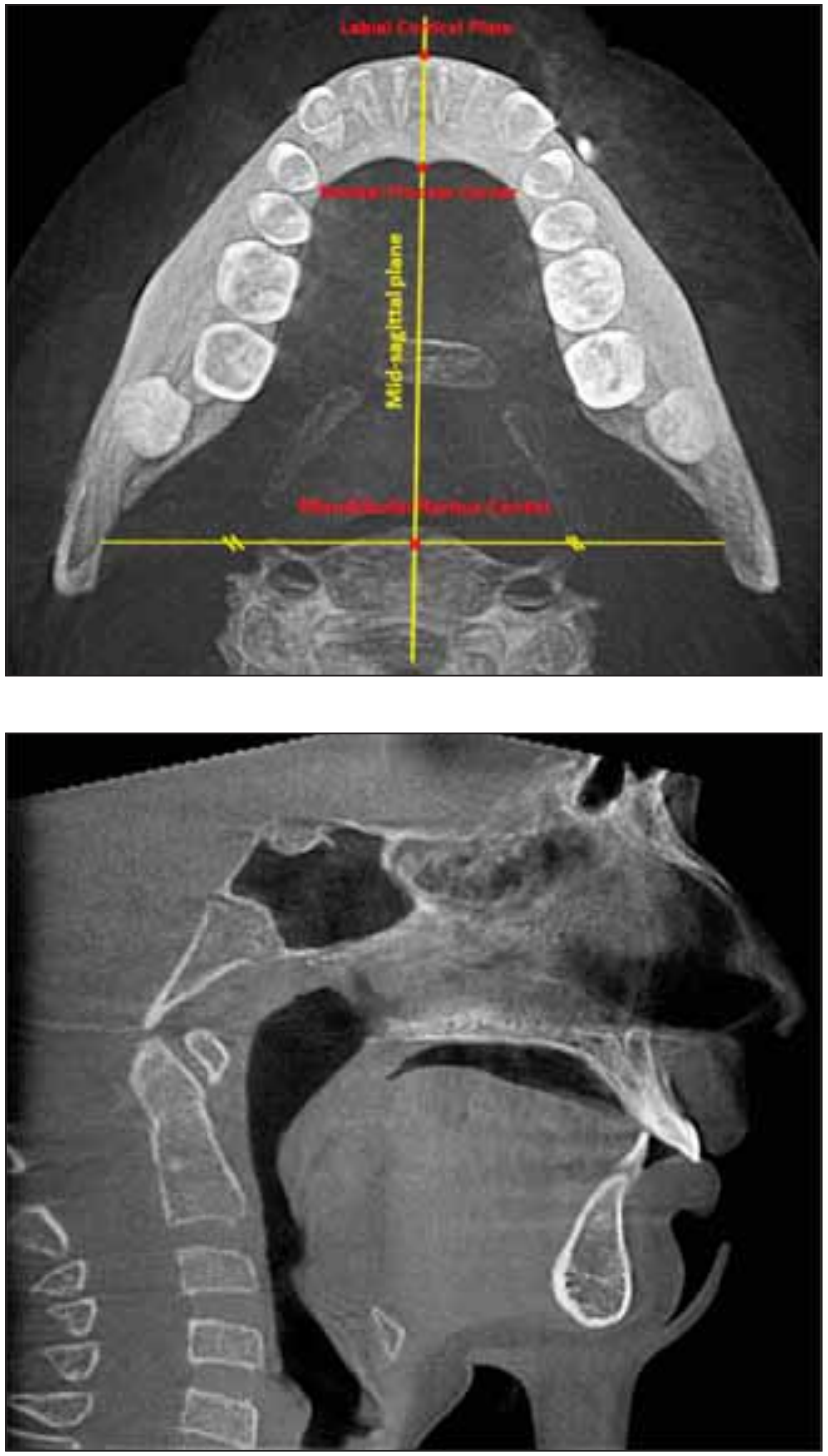

FIGURE 2. Definition of the mid-sagittal plane

\section{Mandibular symphysis study}

Six anatomic landmarks and two axes were considered in the mandibular symphysis study (Table 1, Fig. 3).

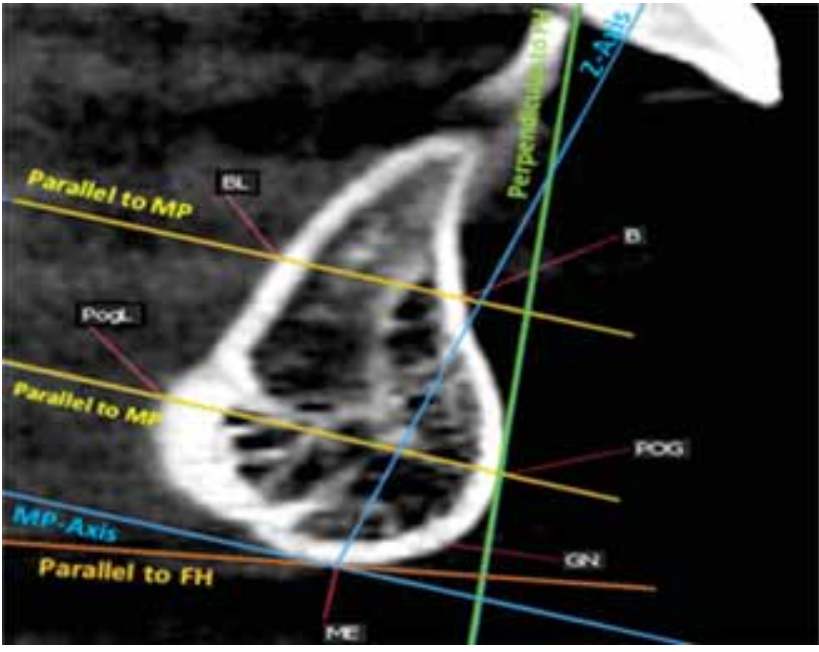

FIGURE 3. Reference points and axis used for mandibular symphysis morphology analysis

Measurement of symphysis on the CBCT image

The area of the mandibular symphysis, six lines, and four angles were considered in the mandibular symphysis study (Table 2, Fig. 4).

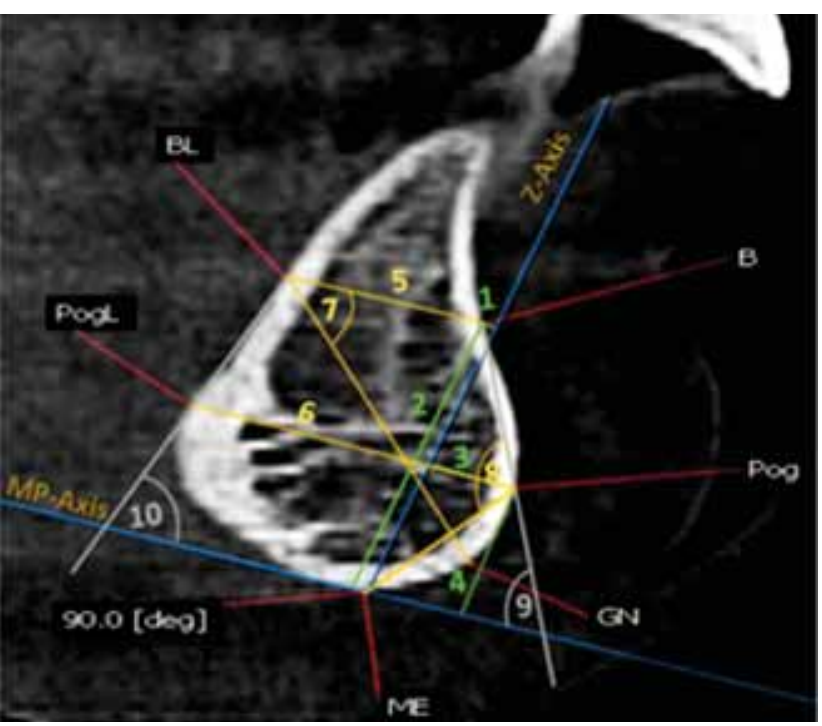

FIGURE 4. Measurements used on mandibular symphysis 1-Z; 2-B-MP; 3-POG-Z; 4-POG-MP; 5-B-BL; 6-POG-POGL; 7-Angle: B-BL-GN; 8-Angle: B-POG-ME; 9-Angle: B-POG

TABLE 1. Reference points and axis used for mandibular symphysis morphology analysis

\begin{tabular}{|c|c|c|}
\hline $\begin{array}{l}\text { Reference points and } \\
\text { axis }\end{array}$ & Definition & Reference \\
\hline \multicolumn{3}{|c|}{ Buccal Points } \\
\hline ME & $\begin{array}{l}\text { By using a line parallel to } \mathrm{FH} \text {, and move the straight edge upward until it first touches the } \\
\text { inferior border of the mandibular symphysis. }\end{array}$ & (33) \\
\hline B & $\begin{array}{l}\text { By using a line perpendicular to } \mathrm{FH}, \text { point } \mathrm{B} \text { is the furthest posterior point in the } \\
\text { concavity between the chin and mandibular alveolar process. }\end{array}$ & (33) \\
\hline POG & By moving the perpendicular to FH forward then back to where it first touches the chin. & (33) \\
\hline GN & In the midway between POG and Me, on the outer line of the symphysis. & (33) \\
\hline \multicolumn{3}{|c|}{ Axis } \\
\hline MP-Axis & $\begin{array}{l}\text { The line connecting } \\
\text { between point Me and point Go }\end{array}$ & (34) \\
\hline Z-Axis & A line perpendicular to the mandibular plane through menton. & (34) \\
\hline \multicolumn{3}{|c|}{ Lingual points } \\
\hline $\mathrm{Bl}$ & A point on the lingual outline of the symphysis drawn from B parallel to MP-Axis. & (34) \\
\hline POGL & A point on the lingual outline of the symphysis drawn from POG parallel to MP-Axis. & (34) \\
\hline
\end{tabular}


TABLE 2. Definitions of measurements used on mandibular symphysis

\begin{tabular}{|c|c|c|c|}
\hline $\begin{array}{l}\text { Mandibular } \\
\text { Symphysis } \\
\text { Parameters }\end{array}$ & Definition & Figure number & Reference \\
\hline \multicolumn{4}{|c|}{ Linear measurements (mm) } \\
\hline B-Z Axis & The symphysis thickness at point B. i.e. distance from B to the z-axis. & 1 & $(34)$ \\
\hline B-MP Axis & The symphysis height at point B. i.e. distance from B to MP axis. & 2 & (34) \\
\hline POG-Z Axis & The symphysis thickness at point POG. i.e. distance from POG to the z-axis. & 3 & $\mathrm{~N} / \mathrm{A}$ \\
\hline POG-MP Axis & The symphysis height at point POG. i.e. distance from POG to MP axis. & 4 & $\mathrm{~N} / \mathrm{A}$ \\
\hline B-BL & The symphysis thickness at point B. i.e. distance from B to the BL. & 5 & (34) \\
\hline POG-POGL & The symphysis thickness at point POG i.e distance from POG to the POGL. & 6 & (34) \\
\hline \multicolumn{4}{|c|}{ Angular measurements (degrees) } \\
\hline B-BL-GN & $\begin{array}{l}\text { The angle between point } B \text {, point } B L \text {, and } G n \text {. It gives an indirect reflection of the } \\
\text { height of the mandibular symphysis. }\end{array}$ & 7 & (20) \\
\hline B-POG-ME & $\begin{array}{l}\text { The angle formed between point B, } \\
\text { POG and Me. It reflects the convexity of the mandibular symphysis. }\end{array}$ & 8 & (20) \\
\hline B-POG-MP Axis & $\begin{array}{l}\text { The angle between a line connecting point B to point POG and the mandibular } \\
\text { plane. It reflects the inclination of the buccal skeletal part of the mandibular } \\
\text { symphysis in relation to the mandibular plane. }\end{array}$ & 9 & (20) \\
\hline $\begin{array}{l}\text { BL-POGL-MP } \\
\text { Axis }\end{array}$ & $\begin{array}{l}\text { The angle between a line connecting point } \mathrm{BL} \text { to point POGL and the mandibular } \\
\text { plane. It reflects the inclination of the lingual skeletal part of the mandibular } \\
\text { symphysis in relation to the mandibular plane. }\end{array}$ & 10 & N/A \\
\hline \multicolumn{4}{|c|}{ Area measurement $\left(\mathrm{mm}^{2}\right)$} \\
\hline MS & $\begin{array}{l}\text { Basal bone cross-sectional area (area outlined by mandibular symphysis surface } \\
\text { and line parallel to MP through B) }\end{array}$ & & $(20,34)$ \\
\hline
\end{tabular}

\section{Lateral cephalometric analysis}

Several studies have confirmed that CBCT-derived 2-dimensional lateral cephalograms can be used as an alternative to traditional cephalometric images and that it is more accurate for most linear measurements (35-37).

The cephalometric evaluation of the different vertical facial patterns was carried out according to Björk and Jarabak (Table 3, Fig. 5).

\section{Error of method}

All measurements were performed by one researcher using the CBCT software, duplicate tracings of all landmarks were repeated independently a month later by the second researcher to test for

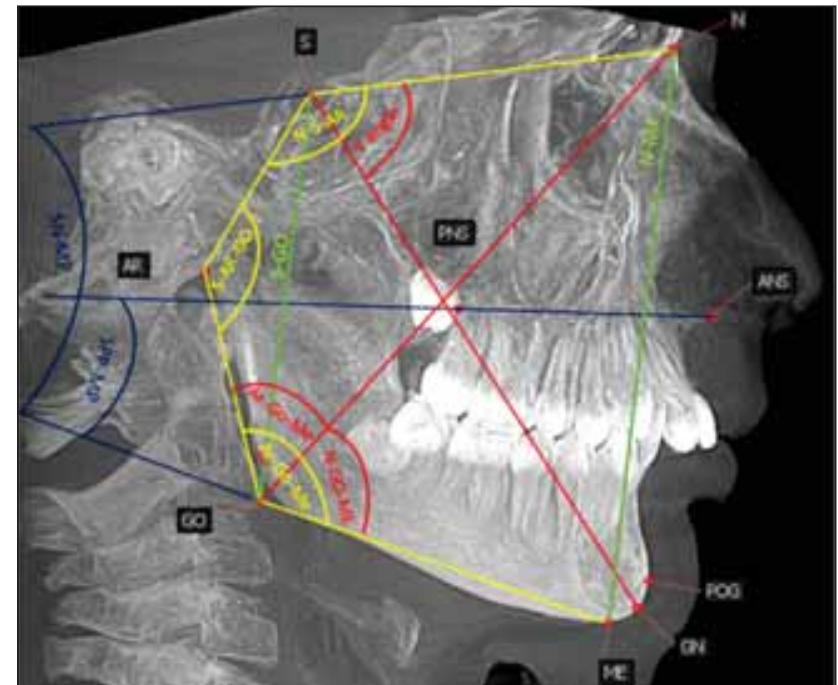

FIGURE 5. Measurements used on cephalometric images

TABLE 3. Definitions of measurements used on lateral cephalometric

\begin{tabular}{|c|c|c|c|}
\hline Cephalometric parameters & Definition & Reference \\
\hline \multicolumn{5}{|c|}{ Angular measurements (degrees) } & $(13,19,38-41)$ \\
\hline N-S-AR & Saddle angle: an angle between anterior and posterior cranial base & $(13,19,38-41)$ \\
\hline S-AR-GO & Articular angle: an angle between posterior cranial base and mandibular ramus & $(13,19,38-41)$ \\
\hline AR-GO-ME & Gonial angle: an angle between mandibular ramus and mandibular body & $(13,19,38-41)$ \\
\hline Bjork's sum & sum of angles Saddle angle (S), Articular angle (Ar), and Gonial angle (Go) & $(13,19,38-41)$ \\
\hline SN-MP & an angle between the anterior cranial base and mandibular plane & $(13,19,38-41)$ \\
\hline SPP-MP & B angle: an angle between the palatal plane and mandibular plane & $(42-45)$ \\
\hline AR-GO-N & Upper Gonial angle (Go1): an angle between Mandibular ramus and Gonion-Nasion line & $(42-45)$ \\
\hline N-GO-ME & Lower Gonial angle (Go2): an angle between Gonion - Nasion line and Mandibular plane & $(42-45)$ \\
\hline Y angle & Growth axis angle: an angle between anterior cranial base and sella - gnathion line & Linear measurements (mm) \\
\hline S-GO & \multicolumn{2}{|c|}{ Posterior facial height: A linear distance from Sella to Gonion } & $(42-45)$ \\
\hline N-ME & Anterior facial height: A linear distance from Nasion to Menton & Ratio & $(42-45)$ \\
\hline FHR & Jarabak ratio: the proportion between the posterior and the anterior facial height & (42-45) \\
\hline
\end{tabular}


the reliability. The data collected were examined using paired t-tests. Linear measurements were accurate to the nearest $0.01 \mathrm{~mm}$, angular measurements were accurate to the nearest 0.01 degrees, and the measurement of the mandibular symphysis area was accurate to the nearest $0.01 \mathrm{~mm}^{2}$. The ttest performed on the two sets of data did not show a significant difference.

\section{Statistical method}

The ANOVA test was carried out to determine the presence of statistically significant differences between the three groups of an independent variable on the continuous dependent variable. The Pearson correlation coefficient (r) was used to examine the strength and direction of the linear relationship between two continuous variables. P-value less than or equal to 0.05 was considered statistically significant. All statistical analyses were performed using Stata v.6.

\section{RESULTS}

The table above shows that the variables relating to the width of the MS, Such as B-Z axis, POG$\mathrm{Z}$ axis, $\mathrm{B}-\mathrm{BL}$ and $\mathrm{POG}-\mathrm{POGL}$ presented an inverse correlation to the vertical facial patterns. Where the lowest values of the above parameters were observed in the vertical growth subjects. On the other hand, a positive correlation was established between the variables relating to the length of the MS, such as B-MP axis and POG-MP axis, with the vertical facial patterns. Where the highest values of the above parameters were observed in the vertical growth subjects.
Moreover, a positive correlation was observed between the convexity parameter (B-POG-Me) with the vertical facial patters. Where the highest values were observed in the vertical growth subjects. A positive correlation was also established between the inclination parameter (B-POG-MP axis) with the vertical facial patterns. Where the highest values were observed in the vertical growth subjects

Furthermore, a statistically significant relationship between B-BL $\left(\mathrm{mm}^{2}\right)$ and the vertical growth patterns was noted; these values were 231.90, 216.34 and 197.13 in normal, horizontal and vertical growth patterns respectively. Interestingly, there was no statistically significant relationship between B-BL-GN, and BL-POGL-MP axis with the growth patterns.

Separate analyses were conducted for females (Table 5) and males (Table 6). It can be noted that the overall results are similar for both sexes.

A statistically significant inversed correlation was observed between B-Z axis, POG-Z axis, $\mathrm{B}-\mathrm{BL}$, and POG-POGL and growth patterns.

In addition, a statistically significant positive correlation between B-MP axis, POG-MP axis, BPOG-Me, and B-POG-MP axis and growth Patterns.

Moreover, a statistically significant relationship between B-BL (mm2) and growth pattern was observed; this variable was larger in the normal growth sample.

However, a statistically significant relationship between B-BL-GN, and BL-POGL-MP axis and growth patterns was not shown.

TABLE 4. The relationship between the mandibular symphysis parameters and vertical facial patterns in the general's sample

\begin{tabular}{|c|c|c|c|c|c|c|c|}
\hline & \multicolumn{6}{|c|}{ Vertical Facial Pattern } & \multirow[t]{2}{*}{$\begin{array}{c}\text { Mandibular symphysis } \\
\text { parameters }\end{array}$} \\
\hline & \multicolumn{2}{|c|}{ Vertical } & \multicolumn{2}{|c|}{ Normal } & \multicolumn{2}{|c|}{ Horizontal } & \\
\hline & \multicolumn{2}{|c|}{17} & \multicolumn{2}{|c|}{47} & \multicolumn{2}{|c|}{36} & $\mathbf{N}$ \\
\hline $\mathrm{p}$ value & SD & Mean & SD & Mean & SD & Mean & \\
\hline$<0.0001$ & 1.28 & -3.83 & 1.22 & -3.03 & 1.83 & -1.76 & B-Z axis \\
\hline 0.0002 & 2.39 & 20.25 & 1.27 & 18.98 & 1.74 & 17.41 & B-MP axis \\
\hline$<0.0001$ & 0.68 & 1.12 & 0.80 & 2.16 & 0.93 & 3.77 & POG-Z axis \\
\hline$<0.0001$ & 0.84 & 10.20 & 1.16 & 9.15 & 1.22 & 8.36 & POG-MP axis \\
\hline 0.0017 & 1.15 & 6.64 & 1.68 & 7.49 & 1.72 & 8.55 & B-BL \\
\hline 0.0009 & 2.41 & 12.10 & 1.78 & 13.56 & 2.26 & 15.01 & POG-POGL \\
\hline 0.0925 & 5.20 & 50.33 & 5.6 & 47.94 & 6.12 & 47.07 & B-BL-GN \\
\hline$<0.0001$ & 10.38 & 147.34 & 5.95 & 136.96 & 9.60 & 126.35 & B-POG-Me \\
\hline 0.0388 & 7.53 & 65.66 & 2.78 & 63.88 & 7.27 & 60.60 & B-POG-MP axis \\
\hline 0.2279 & 8.16 & 85.93 & 7.59 & 84.50 & 8.89 & 84.16 & BL-POGL-MP axis \\
\hline 0.0037 & 16.58 & 197.13 & 18.30 & 231.90 & 17.43 & 216.34 & B-BL $\left(\mathrm{mm}^{2}\right)$ \\
\hline
\end{tabular}


TABLE 5. The relationship between the mandibular symphysis parameters and vertical facial patterns in the female's sample

\begin{tabular}{|c|c|c|c|c|c|c|c|}
\hline & \multicolumn{6}{|c|}{ Vertical Facial Pattern } & \multirow{2}{*}{$\begin{array}{c}\text { Mandibular symphysis } \\
\text { parameters }\end{array}$} \\
\hline & \multicolumn{2}{|c|}{ Vertical } & \multicolumn{2}{|c|}{ Normal } & \multicolumn{2}{|c|}{ Horizontal } & \\
\hline & \multicolumn{2}{|c|}{10} & \multicolumn{2}{|c|}{31} & \multicolumn{2}{|c|}{17} & $\mathbf{N}$ \\
\hline $\mathrm{p}$ value & SD & Mean & SD & Mean & SD & Mean & \\
\hline 0.0001 & 0.25 & -3.15 & 1.19 & -2.70 & 0.74 & -1.45 & B-Z axis \\
\hline 0.045 & 0.65 & 20.34 & 1.51 & 19.07 & 1.98 & 17.08 & B-MP axis \\
\hline$<0.0001$ & 0.91 & 1.12 & 0.88 & 2.21 & 0.48 & 3.58 & POG-Z axis \\
\hline$<0.0001$ & 0.70 & 10.05 & 0.84 & 9.20 & 1.39 & 8.00 & POG-MP axis \\
\hline 0.0179 & 1.49 & 6.69 & 1.81 & 7.64 & 2.08 & 8.07 & B-BL \\
\hline 0.0121 & 3.13 & 11.74 & 2.18 & 12.97 & 1.89 & 14.13 & POG-POGL \\
\hline 0.06751 & 4.69 & 49.30 & 5.46 & 48.42 & 6.98 & 48.75 & B-BL-GN \\
\hline$<0.0001$ & 9.03 & 149.95 & 5.92 & 139.85 & 7.63 & 128.08 & B-POG-ME \\
\hline 0.0019 & 3.68 & 66.98 & 2.08 & 65.70 & 3.04 & 63.13 & B-POG-MP axis \\
\hline 0.2405 & 7.83 & 85.93 & 8.78 & 85.13 & 7.11 & 84.75 & BL-POGL-MP axis \\
\hline 0.0276 & 15.26 & 191.04 & 18.19 & 210.51 & 17.38 & 197.06 & B-BL $\left(\mathrm{mm}^{2}\right)$ \\
\hline
\end{tabular}

TABLE 6. The relationship between the mandibular symphysis parameters and vertical facial patterns in the male's sample

\begin{tabular}{|c|c|c|c|c|c|c|c|}
\hline & \multicolumn{6}{|c|}{ Vertical Facial Pattern } & \multirow{2}{*}{$\begin{array}{l}\text { Mandibular symphysis } \\
\text { parameters }\end{array}$} \\
\hline & \multicolumn{2}{|c|}{ Vertical } & \multicolumn{2}{|c|}{ Normal } & \multicolumn{2}{|c|}{ Horizontal } & \\
\hline & \multicolumn{2}{|c|}{7} & \multicolumn{2}{|c|}{16} & \multicolumn{2}{|c|}{19} & $\mathbf{N}$ \\
\hline$p$ value & SD & Mean & SD & Mean & SD & Mean & \\
\hline 0.0029 & 1.39 & -4.79 & 1.02 & -3.67 & 2.42 & -2.04 & B-Z axis \\
\hline$<0.0001$ & 1.84 & 20.12 & 1.87 & 18.80 & 1.47 & 17.71 & B-MP axis \\
\hline$<0.0001$ & 0.11 & 1.11 & 0.61 & 2.06 & 1.20 & 3.94 & POG-Z axis \\
\hline 0.0001 & 1.31 & 10.42 & 0.69 & 9.06 & 0.98 & 8.69 & POG-MP axis \\
\hline 0.001 & 1.45 & 6.58 & 0.11 & 7.19 & 1.21 & 8.98 & B-BL \\
\hline$<0.0001$ & 0.48 & 12.61 & 1.20 & 14.71 & 1.30 & 15.80 & POG-POGL \\
\hline 0.0018 & 3.89 & 51.8 & 5.09 & 47.01 & 5.93 & 45.56 & B-BL-GN \\
\hline$<0.0001$ & 5.34 & 143.62 & 10.69 & 131.37 & 11.06 & 124.81 & B-POG-Me \\
\hline 0.0235 & 9.19 & 63.77 & 3.67 & 60.35 & 9.35 & 58.33 & B-POG-MP axis \\
\hline 0.1302 & 5.56 & 85.84 & 4.43 & 83.27 & 10.19 & 83.63 & BL-POGL-MP axis \\
\hline$<0.0001$ & 14.75 & 205.82 & 18.60 & 273.34 & 16.25 & 233.59 & B-BL $\left(\mathrm{mm}^{2}\right)$ \\
\hline
\end{tabular}

TABLE 7. Results of the Pearson's correlation between the measurements used on mandibular symphysis and the parameters of vertical facial patterns in the male's sample

\begin{tabular}{|c|c|c|c|c|c|c|c|c|c|c|c|c|}
\hline \multicolumn{12}{|c|}{ Male } & \multirow[b]{2}{*}{ A } \\
\hline $\begin{array}{c}\text { FHR } \\
\text { Ratio } \\
\end{array}$ & N-ME & S-GO & $\begin{array}{c}\text { NS/MP- } \\
\text { Angle }\end{array}$ & B-Angle & Y-Angle & $\begin{array}{l}\text { SUM } \\
\text { Bjork }\end{array}$ & $\begin{array}{c}\text { GO- } \\
\text { Angle }\end{array}$ & $\begin{array}{l}\text { GO2- } \\
\text { Angle }\end{array}$ & $\begin{array}{l}\text { G01- } \\
\text { Angle }\end{array}$ & AR-Angle & S-Angle & \\
\hline $0.15 \Delta$ & $-0.49 \nabla$ & $-0.28 \nabla$ & $-0.28 \nabla$ & $-0.57 \nabla \nabla$ & $0.07 \Delta$ & $-0.27 \nabla$ & $-0.52 \nabla \nabla$ & $-0.64 \nabla \nabla$ & $-0.07 \nabla$ & $0.07 \Delta$ & $0.63 \Delta \Delta$ & B-Z Axis \\
\hline$-0.02 \nabla$ & $0.67 \Delta \Delta$ & $0.52 \Delta \Delta$ & $0.29 \Delta$ & $0.40 \Delta$ & $0.47 \Delta$ & $0.29 \Delta$ & $0.10 \Delta$ & $0.39 \Delta$ & $-0.31 \nabla$ & $0.14 \Delta$ & $-0.08 \nabla$ & B-MP Axis \\
\hline $0.12 \Delta$ & $-0.67 \nabla \nabla$ & $-0.45 \nabla$ & $-0.42 \nabla$ & $-0.64 \nabla \nabla$ & $-0.41 \nabla$ & $-0.43 \nabla$ & $-0.30 \nabla$ & $-0.70 \nabla \nabla$ & $0.37 \Delta$ & $-0.08 \nabla$ & $0.20 \Delta$ & POG-Z Axis \\
\hline$-0.04 \nabla$ & $0.54 \Delta \Delta$ & $0.40 \triangle$ & $0.32 \triangle$ & $0.44 \Delta$ & $0.34 \Delta$ & $0.32 \triangle$ & $0.30 \Delta$ & $0.52 \triangle \Delta$ & $-0.14 \nabla$ & $-0.39 \nabla$ & $0.66 \Delta \Delta$ & $\begin{array}{l}\text { POG-MP } \\
\text { Axis }\end{array}$ \\
\hline $0.34 \Delta$ & $-0.40 \nabla$ & $-0.09 \nabla$ & $-0.49 \nabla$ & $-0.53 \nabla \nabla$ & $-0.46 \nabla$ & $-0.49 \nabla$ & $-0.43 \nabla$ & $-0.49 \nabla$ & $-0.11 \nabla$ & $0.03 \Delta$ & $0.16 \Delta$ & B-BL \\
\hline $0.23 \Delta$ & $-0.09 \nabla$ & $0.08 \Delta$ & $-0.33 \nabla$ & $-0.43 \nabla$ & $-0.09 \nabla$ & $-0.33 \nabla$ & $-0.62 \nabla \nabla$ & $-0.46 \nabla$ & $-0.44 \nabla$ & $0.63 \Delta \Delta$ & $-0.46 \nabla$ & POG-POGL \\
\hline$-0.08 \nabla$ & $0.42 \Delta$ & $0.29 \Delta$ & $0.27 \Delta$ & $0.24 \Delta$ & $0.59 \Delta \Delta$ & $0.27 \Delta$ & $-0.02 \nabla$ & $0.15 \Delta$ & $-0.21 \nabla$ & $0.21 \Delta$ & 0.00 & B-BL-GN \\
\hline$-0.01 \nabla$ & $0.61 \Delta \Delta$ & $0.49 \Delta$ & $0.34 \Delta$ & $0.42 \Delta$ & $0.67 \Delta \Delta$ & $0.35 \Delta$ & $-0.02 \nabla$ & $0.42 \Delta$ & $-0.53 \nabla \nabla$ & $0.18 \Delta$ & $0.20 \Delta$ & B-POG-ME \\
\hline $0.10 \Delta$ & $0.25 \Delta$ & $0.27 \Delta$ & $0.08 \triangle$ & $-0.03 \nabla$ & $0.59 \Delta \Delta$ & $0.09 \Delta$ & $-0.39 \nabla$ & $-0.11 \nabla$ & $\nabla \nabla$ & $0.36 \Delta$ & $0.27 \Delta$ & $\begin{array}{c}\text { B-POG/MP } \\
\text { Axis }\end{array}$ \\
\hline $0.19 \Delta$ & $-0.14 \nabla$ & 0.00 & $-0.30 \nabla$ & $-0.05 \nabla$ & $-0.79 \nabla \nabla$ & $-0.30 \nabla$ & $0.37 \Delta$ & $09 \Delta$ & $0.49 \Delta$ & $-0.52 \nabla \nabla$ & $-0.20 \nabla$ & $\begin{array}{c}\text { BL-POGL/ } \\
\text { MP Axis }\end{array}$ \\
\hline $0.11 \Delta$ & $0.68 \Delta \Delta$ & $0.61 \Delta \Delta$ & $0.14 \Delta$ & $0.24 \Delta$ & $0.36 \Delta$ & $0.15 \Delta$ & $-0.10 \nabla$ & $0.28 \Delta$ & $-0.50 \nabla \nabla$ & $0.26 \Delta$ & $-0.10 \nabla$ & B-BL-Area \\
\hline
\end{tabular}

$\Delta$ : Positive weak strength of correlation; $\mathbf{\Delta} \mathbf{\Delta}$ : Positive Moderate strength of correlation

$\nabla$ : Negative weak strength of correlation; $\nabla \nabla$ : Negative Moderate strength of correlation 
The results were similar between male's and female's samples, except for the relationship between B-BL-GN and vertical facial patterns in the male's sample.

Data in Table 7 show that the correlations in the males sample was generally uneven between positive weak correlation and negative weak correlation with the exception of:

- B-Z Axis showed a moderate positive correlation to the S-Angle and moderate negative correlations to GO2-Angle, GO-Angle and B-Angle.

- B-MP Axis showed a moderate positive correlation to $\mathrm{S}-\mathrm{GO}$ and $\mathrm{N}-\mathrm{ME}$

- POG-Z Axis showed a moderate negative correlation to GO2-Angle, B-Angle and N-ME.

- POG-MP Axis showed a moderate positive correlation with the S-Angle, GO2-Angle, and N-ME.

- B-BL showed a moderate negative correlation with the B-Angle.

- POG-POGL showed a moderate positive correlation to AR-Angle and a moderate negative correlation to GO-Angle.

- B-BL-GN showed a moderate positive correlation to the Y-Angle.

- B-POG-ME showed a moderate negative correlation to (GO1-Angle) and moderate positive correlations to Y-Angle and N-ME.

- B-POG/MP Axis showed a moderate negative correlation to GO1-Angle and a moderate positive correlation to Y-Angle.
- BL-POGL/MP Axis showed moderate negative correlations to AR-Angle and Y-Angle.

- B-BL-Area showed a moderate negative correlation to GO1-Angle and moderate positive correlations to S-GO and N-ME.

Table 8 generally noted that the correlations for the sample of females was uneven between a positive weak correlation and a negative weak correlation with the exception of:

- B-Z Axis presented a moderate positive correlation to the FHR Ratio.

- POG-Z Axis showed a strong negative correlation to the GO2-Angle, SUM Bjork and NS/MP-Angle, a strong positive correlation to the FHR Ratio, a moderate negative correlation to the GO-Angle and B-Angle, and a moderate positive correlation to S-GO.

- POG-MP Axis indicated a moderate positive correlation to the GO2-Angle, SUM Bjork, B-Angle and NS/MP-Angle

- B-POG-ME showed a moderate positive correlation to the GO2-Angle, GO-Angle, YAngle and B-Angle, a strong positive correlation to SUM Bjork and NS/MP-Angle, a moderate negative correlation to $\mathrm{S}-\mathrm{GO}$, and a strong negative correlation to FHR Ratio.

Data from Table 9 showed fluctuating trends (weak positive and weak negative) for all samples with the exception for:

- B-Z Axis showed a moderate negative correlation to GO2-Angle

TABLE 8. Results of the Pearson's correlation between the measurements used on mandibular symphysis and the parameters of vertical facial patterns in the female's sample

\begin{tabular}{|c|c|c|c|c|c|c|c|c|c|c|c|c|}
\hline \multicolumn{12}{|c|}{ Female } & \multirow[b]{2}{*}{ B } \\
\hline FHR Ratio & N-ME & S-GO & $\begin{array}{l}\text { NS/MP- } \\
\text { Angle }\end{array}$ & B-Angle & Y-Angle & SUM Bjork & GO-Angle & G02-Angle & $\begin{array}{l}\text { G01- } \\
\text { Angle }\end{array}$ & $\begin{array}{c}\text { AR- } \\
\text { Angle }\end{array}$ & S-Angle & \\
\hline $0.53 \Delta \Delta$ & $-0.38 \nabla$ & $0.32 \Delta$ & $-0.44 \nabla$ & $-0.23 \nabla$ & $-0.14 \nabla$ & $-0.44 \nabla$ & $-0.18 \nabla$ & $-0.40 \nabla$ & $0.10 \Delta$ & $-0.24 \nabla$ & $0.08 \Delta$ & B-Z Axis \\
\hline$-0.14 \nabla$ & $0.31 \Delta$ & $0.02 \Delta$ & $0.14 \Delta$ & $0.27 \Delta$ & $0.20 \Delta$ & $0.15 \Delta$ & $-0.24 \nabla$ & $0.05 \Delta$ & $-0.37 \nabla$ & $0.38 \Delta$ & 0.00 & B-MP Axis \\
\hline $0.86 \Delta \Delta \Delta$ & $-0.41 \nabla$ & $0.65 \Delta \Delta$ & $-0.87 \nabla \nabla \nabla$ & $-0.53 \nabla \nabla$ & $-0.49 \nabla$ & $-0.86 \nabla \nabla \nabla$ & $-0.55 \nabla \nabla$ & $-0.82 \nabla \nabla \nabla$ & $-0.06 \nabla$ & $-0.14 \nabla$ & $-0.04 \nabla$ & POG-Z Axis \\
\hline$-0.58 \nabla \nabla$ & $0.25 \Delta$ & $-0.47 \nabla$ & $0.64 \Delta \Delta$ & $0.57 \Delta \Delta$ & $0.44 \Delta$ & $0.63 \Delta \Delta$ & $0.49 \Delta$ & $0.58 \Delta \Delta$ & $0.18 \Delta$ & $-0.18 \nabla$ & $0.33 \Delta$ & POG-MP Axis \\
\hline $0.16 \Delta$ & $-0.40 \nabla$ & $-0.04 \nabla$ & $-0.17 \nabla$ & $-0.48 \nabla$ & $-0.07 \nabla$ & $-0.18 \nabla$ & $0.02 \Delta$ & $-0.20 \nabla$ & $0.19 \Delta$ & $-0.25 \nabla$ & $0.13 \Delta$ & B-BL \\
\hline $0.06 \Delta$ & $-0.04 \nabla$ & $0.06 \Delta$ & $-0.14 \nabla$ & $-0.49 \nabla$ & $-0.05 \nabla$ & $-0.13 \nabla$ & $-0.23 \nabla$ & $-0.24 \nabla$ & $-0.11 \nabla$ & $0.07 \Delta$ & $0.09 \Delta$ & POG-POGL \\
\hline $0.13 A$ & $0.21 \Delta$ & $0.23 \Delta$ & $-0.10 \nabla$ & $0.25 \Delta$ & $0.02 \Delta$ & $-0.09 \nabla$ & $-0.25 \nabla$ & $-0.08 \nabla$ & $-0.27 \nabla$ & $0.27 \Delta$ & $-0.14 \nabla$ & B-BL-GN \\
\hline$-0.80 \nabla \nabla \nabla$ & $0.33 \Delta$ & $-0.65 \nabla \nabla$ & $0.84 \Delta \Delta \Delta$ & $0.58 \Delta \Delta$ & $0.55 \Delta \Delta$ & $0.83 \Delta \Delta \Delta$ & $0.52 \Delta \Delta$ & $0.75 \Delta \Delta$ & $0.07 \Delta$ & $0.09 \Delta$ & $0.15 \Delta$ & B-POG-ME \\
\hline$-0.10 \nabla$ & $0.12 \Delta$ & $-0.05 \nabla$ & $0.22 \Delta$ & $0.26 \Delta$ & $0.34 \Delta$ & $0.21 \Delta$ & $-0.03 \nabla$ & $0.18 \Delta$ & $-0.20 \nabla$ & $0.25 \Delta$ & $-0.05 \nabla$ & $\begin{array}{c}\text { B-POG/MP } \\
\text { Axis }\end{array}$ \\
\hline $0.20 \Delta$ & $-0.33 \nabla$ & $0.02 \Delta$ & $-0.21 \nabla$ & $0.03 \Delta$ & $-0.24 \nabla$ & $-0.21 \nabla$ & $0.12 \Delta$ & $-0.13 \nabla$ & $0.27 \Delta$ & $-0.31 \nabla$ & $0.01 \Delta$ & $\begin{array}{c}\text { BL-POGL/MP } \\
\text { Axis }\end{array}$ \\
\hline$-0.13 \nabla$ & $-0.02 \nabla$ & $-0.13 \nabla$ & $0.07 \Delta$ & $-0.28 \nabla$ & $0.13 \Delta$ & $0.08 \Delta$ & $-0.16 \nabla$ & $-0.09 \nabla$ & $-0.15 \nabla$ & $0.13 \Delta$ & $0.18 \Delta$ & B-BL-Area \\
\hline
\end{tabular}

$\Delta$ : Positive weak strength of correlation; $\Delta \Delta$ : Positive Moderate strength of correlation;

$\Delta \boldsymbol{\Delta} \Delta$ : Positive Strong strength of correlation

$\nabla$ : Negative weak strength of correlation; $\nabla \nabla$ : Negative Moderate strength of correlation;

$\nabla \nabla \nabla$ : Negative Strong strength of correlation 
TABLE 9. Results of the Pearson's correlation between the measurements used on mandibular symphysis and the parameters of vertical facial patterns in the general's sample

\begin{tabular}{|c|c|c|c|c|c|c|c|c|c|c|c|c|}
\hline \multicolumn{12}{|c|}{ General } & \multirow[b]{2}{*}{ C } \\
\hline FHR Ratio & N-ME & S-GO & $\begin{array}{l}\text { NS/MP- } \\
\text { Angle }\end{array}$ & B-Angle & Y-Angle & $\begin{array}{l}\text { SUM } \\
\text { Bjork }\end{array}$ & GO-Angle & GO2-Angle & $\begin{array}{l}\text { G01- } \\
\text { Angle }\end{array}$ & $\begin{array}{c}\text { AR- } \\
\text { Angle }\end{array}$ & S-Angle & \\
\hline $0.37 \Delta$ & $-0.38 \nabla$ & $0.07 \Delta$ & $-0.36 \nabla$ & $-0.38 \nabla$ & $-0.07 \nabla$ & $-0.36 \nabla$ & $-0.34 \nabla$ & $-0.51 \nabla \nabla$ & $0.03 \Delta$ & $-0.12 \nabla$ & $0.28 \Delta$ & B-Z Axis \\
\hline $0.02 \mathrm{~A}$ & $0.56 \Delta \Delta$ & $0.36 \mathrm{~A}$ & $0.08 \Delta$ & $0.18 \Delta$ & $0.24 \mathrm{~A}$ & $0.08 \Delta$ & $-0.11 \nabla$ & $0.12 \Delta$ & $-0.29 \nabla$ & $0.16 \Delta$ & $0.04 \Delta$ & B-MP Axis \\
\hline $0.68 \Delta \Delta$ & $-0.34 \nabla$ & $0.36 \Delta$ & $-0.76 \nabla \nabla$ & $-0.65 \nabla \nabla$ & $-0.48 \nabla$ & $-0.76 \nabla \nabla$ & $-0.52 \nabla \nabla$ & $-0.81 \nabla \nabla \nabla$ & $0.07 \Delta$ & $-0.20 \nabla$ & $0.15 \Delta$ & POG-Z Axis \\
\hline$-0.34 \nabla$ & $0.39 \Delta$ & $-0.05 \nabla$ & $0.45 \Delta$ & $0.42 \mathrm{~A}$ & $0.38 \Delta$ & $0.44 \Delta$ & $0.38 \Delta$ & $0.47 \Delta$ & $0.07 \Delta$ & $-0.26 \nabla$ & $0.41 \Delta$ & POG-MP Axis \\
\hline $0.33 \Delta$ & $-0.23 \nabla$ & $0.15 \Delta$ & $-0.38 \nabla$ & $-0.58 \nabla \nabla$ & $-0.24 \nabla$ & $-0.38 \nabla$ & $-0.25 \nabla$ & $-0.43 \nabla$ & $0.07 \Delta$ & $-0.21 \nabla$ & $0.24 \Delta$ & B-BL \\
\hline $0.31 \Delta$ & $0.16 \Delta$ & $0.37 \Delta$ & $-0.37 \nabla$ & $-0.61 \nabla \nabla$ & $-0.15 \nabla$ & $-0.37 \nabla$ & $-0.43 \nabla$ & $-0.47 \nabla$ & $-0.15 \nabla$ & $0.02 \Delta$ & $0.19 \Delta$ & POG-POGL \\
\hline 0.00 & $0.26 \Delta$ & $0.15 \Delta$ & $0.08 \Delta$ & $0.27 \mathrm{~A}$ & $0.22 \mathrm{~A}$ & $0.08 \Delta$ & $-0.11 \nabla$ & $0.07 \Delta$ & $-0.24 \nabla$ & $0.26 \Delta$ & $-0.13 \nabla$ & B-BL-GN \\
\hline$-0.58 \nabla \nabla$ & $0.33 A$ & $-0.28 \nabla$ & $0.69 \Delta \Delta$ & $0.57 \Delta \Delta$ & $0.59 \Delta \Delta$ & $0.69 \Delta \Delta$ & $0.37 \Delta$ & $0.65 \Delta \Delta$ & $-0.12 \nabla$ & $0.18 \Delta$ & $0.05 \Delta$ & B-POG-ME \\
\hline$-0.07 \nabla$ & $0.14 \Delta$ & $0.03 \mathrm{~A}$ & $0.18 \Delta$ & $0.16 \Delta$ & $0.42 \Delta$ & $0.18 \Delta$ & $-0.15 \nabla$ & $0.08 \Delta$ & $-0.30 \nabla$ & $0.30 \Delta$ & $0.020 \Delta$ & B-POG/MP Axis \\
\hline $0.07 \Delta$ & $-0.30 \nabla$ & $-0.12 \nabla$ & $-0.11 \nabla$ & $0.12 \Delta$ & $-0.35 \nabla$ & $-0.11 \nabla$ & $0.27 \Delta$ & $0.07 \Delta$ & $0.32 \triangle$ & $-0.30 \nabla$ & $-0.13 \nabla$ & BL-POGL/MP Axis \\
\hline $0.21 \Delta$ & $0.48 \Delta$ & $0.48 \triangle$ & $-0.17 \nabla$ & $-0.31 \nabla$ & $0.06 \Delta$ & $-0.17 \nabla$ & $-0.28 \nabla$ & $-0.18 \nabla$ & $-0.22 \nabla$ & $-0.01 \nabla$ & $0.25 \Delta$ & B-BL-Area \\
\hline
\end{tabular}

$\boldsymbol{\Delta}$ : Positive weak strength of correlation; $\mathbf{\Delta} \mathbf{\Delta}$ : Positive Moderate strength of correlation

$\nabla$ : Negative weak strength of correlation; $\nabla \nabla$ : Negative Moderate strength of correlation; $\nabla \nabla \nabla$ : Negative Strong strength of correlation

- B-MP Axis showed a moderate positive correlation to N-ME

- POG-Z Axis showed a strong negative correlation to $\mathrm{GO} 2$-Angle, moderate negative correlations to GO-Angle, SUM Bjork, BAngle and NS/MP-Angle and a moderate positive correlation to the FHR ratio.

- B-BL showed a moderate negative correlation to B-Angle.

- POG-POGL showed a moderate negative correlation to the B-Angle.

- B-POG-ME showed moderate positive correation to the GO2-Angle, SUM Bjork, YAngle, B-Angle and NS/MP-Angle, and a moderate negative correlation to the FHR ratio.

\section{DISCUSSION}

The results of the study were in agreement with Handelman (5) and Beckmann (46) who reported that hyperdivergent patients present a thinner mandibular symphysis and a thinner alveolar ridge in the anterior region of the mandible, compared to the other facial patterns. This was illustrated by the statistically significant inverse relationship between the (B-Z axis, POG-Z axis, B-BL, and POGPOGL) and the vertical growth patterns.

On the other hand, a statistically significant inverse correlation between the POG-Z axis with the NS/MP-Angle was observed. This was in agreement with the earlier study on the morphology of the symphyseal region in adult Japanese samples, which was based on the divergence of the mandibular plane angle and reported that the alveolar bone thickness was negatively correlated to the mandibular plane angle $(4,15)$.

More recently, cone-beam computed tomography (CBCT) studies of untreated individuals have supported the claims that the total thickness of the mandibular symphysis is greater in short-face subjects as opposed to their long-face counterparts $(47,48)$. Our result was in a good agreement with these studies, where a statistically significant inversed relationship was observed between the B-BL, and the POG-POGL with the vertical growth patterns.

Distance from point $\mathrm{B}$ to $\mathrm{z}$-axis, distance from point $\mathrm{B}$ to point $\mathrm{BL}$, and distance from point $\mathrm{POG}$ to point POGL were studied by Endo (34) and no significant differences in the mandibular thicknesses between the groups were established. This study did not agree with their findings considering that teeth loss leads to counter-clockwise rotation of the mandibular, which in turn increases the thickness of the mandibular symphysis.

The angle B-BL-GN was studied by Al-Khateeb (20) who compared it with anterior-posterior skeletal relationship and noted that the angle B-BL-GN was significantly smaller in Class II than in Class I and III skeletal relationships. In the current study, a statistically significant relationship was not observed between B-BL-GN and the vertical growth patterns, except for the males group.

Patients with a vertical growth pattern, open bite, and high mandibular plane angle have larger vertical dimension of the symphysis $(1,4,11)$. This is in agreement with the study finding where a statistically significant positive relationship between the B-MP axis and POG-MP axis and the vertical growth patterns was observed. 
Inclination of the buccal skeletal part (B-POG/ MP Axis) of the MS, and the convexity of the mandibular symphysis (B-POG-ME) were also studied by Al-Khateeb (20). Their study involved a comparison of these parameters with the anterior-posterior skeletal relationship. They reported that they had no significant difference among Class I, Class II, and Class III skeletal relationships. In this study, however, a statistically significant positive correlation between the convexity of the mandibular symphysis (B-POG-ME) and the inclination of the buccal skeletal part of the mandibular symphysis in relation to the mandibular plane (B-POG/MP Axis) to the vertical growth patterns was observed.

In the present study, the MS area (area outlined by MS surface and the line parallel to MP through B) was studied and a statistically significant relationship with the vertical growth patterns was observed. The MS area was larger in the normal growth sample. This was in disagreement with Endo (34) as they studied the MS cross-sectional area (area outlined by MS surface and line between Id and LId) and noticed that hypodontia groups had a significantly smaller MS area than those without hypodontia, considering that tooth loss leads to counter-clockwise rotation of the mandibular.

On the other hand, the total area confined within the outer border of MS and bounded superiorly by the line connecting Id and the most superior point of the lingual mandibular alveolar crest was studied by Al-Khateeb (20). They reported that the MS area in Class III groups was meaningfully larger than those in Class I and Class II. This was in disagreement with the study findings where the MS area in normal growth subjects was significantly larger than those in the vertical and horizontal groups.

Evaluating the correlation between the morphology and dimension of MS and the vertical facial patterns according to gender, the overall results were similar for both males and females.

\section{REFERENCES}

1. Chung C.J., Jung S., Baik H.S. Morphological characteristics of the symphyseal region in adult skeletal Class III crossbite and openbite malocclusions. Angle Orthod. 2008 Jan; 78(1):38-43.

2. Hoenig J.F. Sliding osteotomy genioplasty for facial aesthetic balance: 10 years of experience. Aesthetic Plast Surg. 2007; 31:384-391.

3. Buschang P.H., Julien K., Sachdeva R., Demirjian A. Childhood and pubertal growth changes of the human symphysis. Angle Orthod. 1992; 62:203-210.

4. Tanaka R., Suzuki H., Maeda H., Kobayashi K. Relationship between an inclination of mandibular plane and a morphology of
Swasty (48) reported that males have a longer mandibular cross-sectional area. In addition, AlKhateeb (20) found that males had a larger B-B1GN angle than females. However, It is important to note that this study did not compare between males and females in terms of numerical values of the parameters; the study focused on relating the males and females with the growth patterns separately.

\section{CONCLUSION}

The convexity of the mandibular symphysis (BPOG-Me) showed the largest correlation to the parameters evaluating the vertical facial patterns. It increased as those parameters increased, except for the S-GO distance and FHR ratio, where it increased as the parameters increased.

The distance from POG to the $\mathrm{z}$-axis (POG-Z Axis) was highly correlated to the parameters evaluating the vertical facial patterns. It increased as the parameters increased, except for the S-GO distance and FHR ratio where it increased as the parameters increased.

The distance from POG to MP axis (POG-MP Axis) showed a large correlation to the parameters evaluating the vertical facial patterns. It increased as the parameters increased, except for the FHR Ratio where it increased as the parameter decreased.

When the parameters evaluating the vertical facial patterns increased, the point B moved closer to the $\mathrm{Z}$-axis and moved away from the $\mathrm{Y}$-axis.

The angle between the palatal plane and the mandibular plane (B-Angle) showed the largest correlation to the measurements used on the mandibular symphysis.

The angle between Gonion - Nasion line and Mandibular plane (GO2-Angle) showed a large correlation to the measurements used on the mandibular symphysis. symphysis (in Japanese). Nippon Kyosei Shika Gakkai Zasshi. 1989; 48:7-20.

5. Handelman C.S. The anterior alveolus: its importance in limiting orthodontic treatment and its influence on the occurrence of iatrogenic sequelae. Angle Orthod. 1996; 66:95-110.

6. Proffit W.R., Whilte R.P., Sarver D.M. Contemporary Treat ment of Dentofacial Deformity. New York, NY: Elsevier Inc; 2003.

7. Haskell B.S. The human chin and its relationship to mandibular morphology. Angle Orthod. 1979; 49:153-166.

8. Kubota M., Nakano H., Sanjo I., Satoh K., Sanjo T., Kamegai T., Ishikawa F. Maxillofacial morphology and masseter muscle thickness in adults. Eur J Orthod. 1998;20:535-542. 
9. Eroz U.B., Ceylan I., Aydemir S. An investigation of mandibular morphology in subjects with different vertical facial growth patterns. Aust Orthod J. 2000; 16:16-22.

10. Haskell B.S. The human chin and its relationship to mandibular morphology. Angle Orthod. 1979; 49:153-166.

11. Ceylan I., Eroz U.B. The effects of overbite on the maxillary and mandibular morphology. Angle Orthod. 2001; 71:110-115.

12. Beckmann S.H., Kuitert R.B., Prahl-Andersen B., Segner D., The R.P., Tuinzing D.B. Alveolar and skeletal dimensions associated with overbite. Am J Orthod Dentofacial Orthop. 1998; 113:443-452.

13. Bjork A. Prediction of mandibular growth rotation. Am J Orthod. 1969; 55:585-599.

14. von Bremen J., Pancherz H. Association between Bjork's structural signs of mandibular growth rotation and skeletofacial morphology. Angle Orthod. 2005; 75:506-509.

15. Nojima K., Nakakawaji K., Sakamoto T., Isshiki Y. Relationships between mandibular symphysis morphology and lower incisor inclination in skeletal class III malocclusion requiring orthognathic surgery. Bull Tokyo Dent Coll. 1998; 39:175-181.

16. Yamada C., Kitai N., Kakimoto N., Murakami S., Furukawa S., Takada K. Spatial relationships between the mandibular central incisor and associated alveolar bone in adults with mandibular prognathism. Angle Orthod. 2007; 77:766-772.

17. Shimomoto Y., Iwasaki Y., Chung C. Y., Muramoto T., Soma K. Effects of occlusal stimuli on alveolar/jaw bone formation. J Dent Res. 2007; 86:47-51.

18. Garn S.M., Lewis B., Vicinus J.H. The inheritance of symphyseal size during growth. Angle Orthod. 1963; 33:222-231.

19. Skieller V.B., Bjork A., Linde-Hansen T. Prediction of mandibular growth rotation evaluated from a longitudinal implant sample. Am J Orthod. 1984; 86:359-370.

20. Al-Khateeb S.N., Al Maaitah E.F., Abu Alhaija E.S., Badran S. A. Mandibular symphysis morphology and dimensions in different anteroposterior jaw relationships. Angle Orthod. 2014 Mar; 84(2):304-9.

21. Farman A.G., Scarfe W.C. Development of imaging selection criteria and procedures should precede cephalometric assessment with cone-beam computed tomography. Am J Orthod Dentofacial Orthop. 2006; 130(2):257-65

22. Kumar V., Ludlow J. B., Mol A., Cevidanes L. Comparison of conventional and cone beam CT synthesized cephalograms. Dentomaxillofac Radiol. 2007; 36(5):263-9.

23. Mah J., Huang J., Bumann A. The cone-beam decision in orthodontics. Proceedings of the 32nd Annual Moyers Symposium Ann Arbor; 2006. p. 59-75.

24. Sarment D.P. Dental applications for cone-beam computed tomography. Proceedings of the 32nd Annual Moyers Symposium. Ann Arbor, 2006.

25. Swennen G.R., Schutyser F. Three-dimensional cephalometry: spiral multi-slice vs cone-beam computed tomography. Am J Orthod Dentofacial Orthop. 2006; 130(3):410-6.

26. Kumar V., Ludlow J., Soares Cevidanes L.H., Mol A. In vivo comparison of conventional and cone beam CT synthesized cephalograms. Angle Orthod. 2008; 78(5):873-9.

27. Ludlow J.B., Davies-Ludlow L.E., Brooks S.L. Dosimetry of two extraoral direct digital imaging devices: NewTom cone beam CT and Orthophos Plus DS panoramic unit. Dentomaxillofac Radiol. 2003; 32(4):229-34

28. Motta A.T. Avaliação da cirurgia de avanço mandibular por meio da superposição de modelos tridimensionais (tese). Rio de Janeiro: Universidade Estadual do Rio de Janeiro; 2007.

29. Marquezan M., Nojima L.I., Freitas A.O., Baratieri C., Alves J.M., Nojima M.C., Araújo M.T. Tomographic mapping of the hard palate and overlying mucosa. Braz Oral Res. 2012 Jan-Feb; 26(1):36-42.
30. Baratieri C., Alves M. Jr., Bolognese A.M., Nojima M.C., Nojima L.I. Changes in skeletal and dental relationship in Class II Division I malocclusion after rapid maxillary expansion: a prospective study. Dental Press J Orthod. 2014 May-Jun; 19(3):75-81.

31. Baratieri C., Nojima L.I., Alves M.J., Souza M.M.G., Nojima M.C.G. Transverse effects of rapid maxillary expansion in Class II malocclusion patients: a cone-beam computed tomography study. Dental Press J Orthod. 2010 set-out; 15(5):89-97.

32. Alves M. Jr., Baratieri C., Nojima L.I. Assessment of mini-implant displacement using cone beam computed tomography. Clin Oral Implants Res. 2011 Oct 22(10):1151-6.

33. Jacobson A., Jacobson R. Radiographic cephalometry: from basics to 3-D imaging / edited. P49-50.

34. Endo T., Ozoe R., Kojima K., Shimooka S. Congenitally missing mandibular incisors and mandibular symphysis morphology. Angle Orthod. 2007 Nov; 77(6):1079-84

35. Moshiri M., Scarfe W.C., Hilgers M.L., Scheetz J.P., Silveira A.M., Farman A.G. Accuracy of linear measurements from imaging plate and lateral cephalometric images derived from cone-beam computed tomography. Am J Orthod Dentofacial Orthop. 2007 Oct; 132(4):550-60.

36. Kumar V., Ludlow J., Soares C. LH., Mol A. In vivo comparison of conventional and cone beam CT synthesized cephalograms. Angle Orthod. 2008 Sep; 78(5):873-9.

37. Ludlow J.B., Gubler M., Cevidanes L., Mol A. Precision of cephalometric landmark identification: cone-beam computed tomography vs conventional cephalometric views. Am J Orthod Dentofacial Orthop. 2009 Sep; 136(3):312.e1-10.

38. Björk A. The face in profile; an anthropological x-ray investigation on Swedish children and conscripts. Svensktandläkare-Tidskrift. 1947; Suppl. 40. (5B)

39. Björk A. The role of genetic and local environmental factors in normal and abnormal morphogenesis. Acta Morphol Neerl Scand 1972; 10:49-58.

40. Björk A., Skieller V. Facial development and tooth eruption: An implant study at the age of puberty. Am J Orthod 1972; 62:339-83

41. Björk A., Skieller V. Normal and abnormal growth of the mandible: A synthesis of longitudinal cephalometric implant studies over a period of 25 years. Eur J Orthod 1983;5:1-46.

42. Jarabak J.R., Fizzell J.A. Technigue and treatment with lightwire edgewise appliance. St Louis: CV Mosby 1972:15-18.

43. Jarabak J.R. Die morphologie und behandlung des deckbisses. Journal of Orofacial Orthopedics Fortschritte der Kieferorthopädie, Volume 36, issue 41975

44. Jarabak J.R. Open bite. Journal of Orofacial Orthopedics Fortschritte der Kieferorthopädie, 44, issue 2, 1983.

45. Siriwat P.P., Jarabak J.R. Malocclusion and Facial Morphology Is there a Relationship? Angle Orthod 1985; SS: 127-38.

46. Beckmann S.H., Kuitert R.B., Prahl A.B., Segner D., The R.P., Tuinzing D.B. Alveolar and skeletal dimensions associated with lower face height. Am J Orthod Dentofacial Orthop. 1998 May; 113(5):498-506.

47. Gracco A., Luca L., Bongiorno M.C., Siciliani G. Computed tomography evaluation of mandibular incisor bony support in untreated patients. Am J Orthod Dentofacial Orthop. 2010; 138:179-187

48. Swasty D., Lee J., Huang J.C., Maki K., Gansky S.A., Hatcher D., Miller A.J. Cross-sectional human mandibular morphology as assessed in vivo by cone-beam computed tomography in patients with different vertical facial dimensions. Am J Orthod Dentofacial Orthop. 2011; 139:e377-389. 